\title{
Aposentadoria na perspectiva de trabalhadores do setor privado
}

\author{
Luciane Santos Machado de Carvalho* \\ Marilsa de Sá Rodrigues** \\ Adriana Leônidas de Oliveira**
}

\begin{abstract}
Resumo
A aposentadoria e a ruptura do vínculo de trabalho podem causar sofrimento aos trabalhadores. O objetivo desse estudo foi analisar a percepção sobre a aposentadoria de pessoas com idade a partir de 45 anos do setor privado e de profissionais de Recursos Humanos envolvidos em Programas de Preparação para Aposentadoria. A metodologia utilizada foi de caráter exploratório e, para a coleta de dados foram realizadas entrevistas semiestruturadas, classificadas em categorias apriorísticas e analisadas por meio da análise de conteúdo. Participaram da pesquisa vinte profissionais selecionados pela rede profissional da pesquisadora e pela técnica "Bola de Neve". Os resultados mostraram a percepção dos participantes quanto ao significado do trabalho como dedicação, realização, fonte de sustento e as perdas em decorrência da aposentadoria. Estas são: assistência médica, ausência da convivência com colegas de trabalho e financeiras. Constatou-se a importância dos Programas de Preparação para Aposentadoria, que oportunizam planejamento e estabelecimento de novos objetivos. Concluiu-se que a aposentadoria foi percebida pelos participantes como oportunidade de maior tempo disponível, qualidade de vida e saúde. Entretanto, demonstraram preocupação em relação ao aspecto financeiro e à manutenção da assistência médica.
\end{abstract}

Palavras-chave: Gestão. Aposentadoria. Preparação para Aposentadoria.

\section{Retirement from the perspective of private sector workers}

\begin{abstract}
Retirement and a break in employment can cause workers suffering. The objective of this study was to analyze the perception about retirement of people aged 45 and over in the private sector and of Human Resources professionals involved in Retirement Preparation Programs. The methodology used was exploratory and, for data collection, semi-structured interviews were carried out, classified into a priori categories and analyzed through content analysis. Twenty professionals participated in the research, selected by the researcher's professional network and by the "Snowball" technique. The results showed the participants' perception of the meaning pf work as dedication, accomplishment, source of support and losses due to retirement. These are the medical assistance, absence from coexistence with co-workers and financiers. The importance of the Retirement Preparation Programs was found to be an opportunity to plan and establish new goals. It was concluded that the retirement was perceived by the participants as an opportunity for more time available, quality of life and health. However, they showed concern regarding the financial aspect and maintenance of medical assistance.
\end{abstract}

Keywords: Management. Retirement. Preparing for Retirement.

* Mestranda no PPG em Gestão e Desenvolvimento Regional - UNITAU.

** Doutora em Administração de Empresas - Mackenzie e Profa. do PPG em Gestão e Desenvolvimento Regional - UNITAU

*** Doutora em Psicologia pela PUCSP e Diretora do Departamento de Psicologia da Universidade - UNITAU 


\section{Introdução}

O trabalho, fonte de riqueza de sentido individual e social, pode ser utilizado como meio de produção da vida e como provedor de subsistência. Além disso, cria sentidos existenciais e contribui na estruturação da identidade e personalidade das pessoas (De Oliveira Borges \& Tamayo, 2001).

No Brasil, as desigualdades de desenvolvimento das classes trabalhadoras corroboram o convívio das várias concepções sobre o trabalho. Assim, há que se destacar a diversidade da realidade atual e demonstrar como os profissionais que se propõem a estudar o trabalho e as questões referentes a ele precisam considerar cada ambiente que se apresenta para as intervenções (Bressan, Mafra, França, Melo \& Loreto, 2012).

A fase de aposentadoria, idealizada social e culturalmente, poderia direcionar o indivíduo para um momento de descanso e gozo de prazeres da vida; no entanto, no Brasil essa expectativa muitas vezes não corresponde à realidade, devido às desigualdades sociais e econômicas existentes. O campo organizacional demanda ações relacionadas à gestão de pessoas, com vistas a empreender formas de garantir um processo de envelhecimento, não como fato consumado de exclusão, mas como um fator natural que pode exigir atenção e preparação dos trabalhadores idosos e em processo de aposentadoria (Dantas \& Oliveira, 2014).

Torna-se relevante, portanto, entender as questões que envolvem o momento da aposentadoria e da transição de carreira como um processo educacional, de preparação e de planejamento, com vistas à demanda de envelhecimento populacional. É relevante, também, verificar como as pessoas percebem esse novo ciclo e se estão se preparando para essa realidade.

\section{Material e método}

Trata-se de um estudo de caráter exploratório, quanto aos objetivos e qualitativo quanto à abordagem.

A amostra foi composta de 3 profissionais da área de Recursos Humanos que participaram ou participam de PPA e de 17 profissionais do setor privado com idade a partir de 45 anos, dos gêneros masculino e feminino. A amostra foi selecionada a partir da rede profissional da pesquisadora e da técnica "Bola de Neve", metodologia utilizada em pesquisas sociais: os participantes iniciais indicam novos participantes que, por sua vez, indicam outros, e assim sucessivamente, até que o objetivo proposto seja alcançado. O ponto de saturação é atingido quando os novos entrevistados passam a repetir conteúdos já obtidos em entrevistas anteriores, sem acrescentar novas informações relevantes à pesquisa (Albuquerque, 2009).

Como instrumento, empregou-se entrevista semiestruturada com roteiro adaptado de Varela (2013), cuja pesquisa foi realizada junto a docentes de uma instituição pública, com o intuito de compreender o significado do trabalho e da aposentadoria, ao comparar as percepções de pré-aposentados e aposentados.

Para a realização do estudo foram utilizados 3 tipos de roteiros. O primeiro deles foi direcionado às pessoas com idade a partir de 45 anos atuantes no mercado de trabalho formal, o segundo, às pessoas com idade a partir de 45 anos que saíram do mercado de trabalho formal, e o terceiro, aos profissionais da área de Recursos Humanos que atuaram ou que ainda estão envolvidos em Programas de Preparação para Aposentadoria - PPA.

As entrevistas individuais, cada uma delas com duração de aproximadamente vinte minutos, foram realizadas presencialmente e também por meio do aplicativo Whatsapp, que permitiu a realização de chamadas em áudio, mediante consentimento dos participantes. A escolha dessa ferramenta teve como intenção não limitar a pesquisadora quanto à localidade dos entrevistados.

Para atingir os objetivos estabelecidos foram definidas categorias apriorísticas conforme três grandes variáveis analíticas: gestão, aposentadoria e preparação para aposentadoria. As categorias foram subdivididas em subcategorias relativas à expectativa de carreira, significado do trabalho, significado da aposentadoria, expectativas sobre a aposentadoria, ganhos e perdas da aposentadoria e percepção sobre a relevância de programas de PPA.

Foram realizados simultaneamente os processos de coleta e análise de dados, com o objetivo de descobrir as variações entre os conceitos e as categorias apriorísticas, até que fosse necessário observar o critério de saturação (Oliveira, 2007).

Os dados foram tratados utilizando-se as técnicas qualitativas da metodologia de Análise de Conteúdo (Bardin, 1977).

Os procedimentos utilizados para fins de coleta e interpretação dos dados seguiram a sequência de pré-análise: as falas dos entrevistados foram transferidas para planilhas no editor Excel da Microsoft Office e elencadas conforme os objetivos específicos da pesquisa, para obtenção da visão global das falas e identificação dos pontos comuns, divergentes e relevantes.

$\mathrm{Na}$ sequência foi feita a exploração do material. As entrevistas transcritas foram classificadas em categorias e subcategorias conforme os objetivos específicos da pesquisa e, por fim, categorizadas e analisadas. 


\section{Resultados}

Os campos dos roteiros utilizados nas entrevistas foram divididos em categorias e subcategorias.

Quadro 1 - Categorias e subcategorias de pesquisa

\begin{tabular}{|c|c|}
\hline Categorias & Subcategorias \\
\hline Sociodemográficas & $\begin{array}{l}\text { Dados de identificação do participante: sexo, } \\
\text { idade, estado civil, arranjo familiar, formação, } \\
\text { área de atuação, tempo de trabalho na empresa, } \\
\text { tempo para aposentadoria, se possui plano de } \\
\text { previdência privada, e faixa de renda familiar. }\end{array}$ \\
\hline Gestão & $\begin{array}{l}\text { Expectativas de carreira, significado do } \\
\text { trabalho. }\end{array}$ \\
\hline Aposentadoria & $\begin{array}{l}\text { Significado, percepções, expectativas e ganhos e } \\
\text { perdas. }\end{array}$ \\
\hline $\begin{array}{l}\text { Preparação para } \\
\text { aposentadoria }\end{array}$ & $\begin{array}{l}\text { Percepção sobre a relevância de programas de } \\
\text { preparação para aposentadoria }\end{array}$ \\
\hline
\end{tabular}

Fonte: Elaborado pela autora, com base em Varela (2013).

O quadro 1 mostra a caracterização dos profissionais da área de Recursos Humanos que atuam ou atuaram em PPA, denominados pela pesquisadora de PRH (Participante de Recursos Humanos) e numerados com algarismos indo-arábicos.

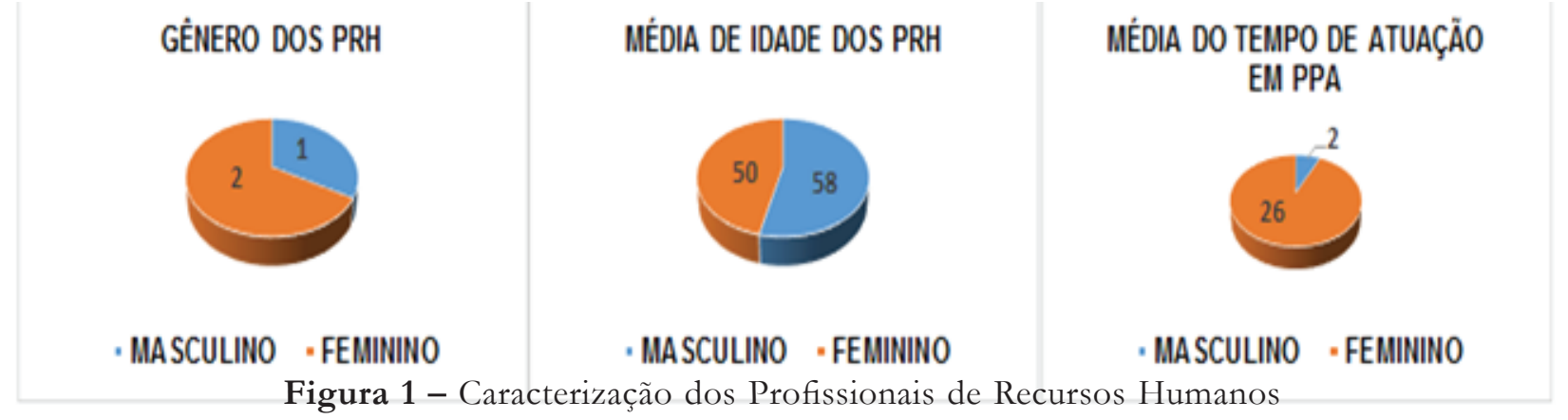

Fonte: Elaborada pela autora a partir dos dados coletados (2019).

A caracterização dos profissionais do setor privado a partir de 45 anos de idade, conforme figura 2, foram denominados pela pesquisadora de PA (Participante) e numerados com algarismos indo-arábicos.

GÊNERO DOS PA

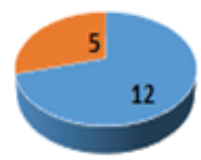

- MASCUUNO - FEMININO

ARRANJO FAMILIAR DOS PA

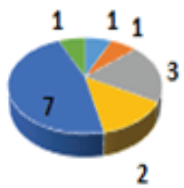

- IRMÃo

" CÔNJUGE

- CÔNJUGE +2 FILHO
ESTADO CIVIL DOSPA

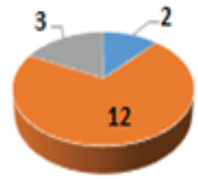

- SOLTERO - CASADO " DIVORCIADO

\section{FORMAÇ̃̃O}

DOS PA

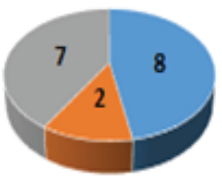

- ENSINO MÉDIO

- ENSINO MÉDIO TÉCNICO

Figura 2 - Características pessoais e de formação dos participantes

Fonte: Elaborada pela autora a partir dos dados coletados (2019). 
Dentre os 17 entrevistados, somente 5 são do gênero feminino, representando 29\% do total, o que pode ser justificado pelo fato de pertencerem ao setor industrial, principalmente da área operacional. A média de idade dos participantes é de 54 anos, sendo predominante o estado civil casado, representado por 12 pessoas, e com arranjo familiar majoritariamente composto por cônjuge e filhos. A maioria das famílias tem até 2 filhos.

Do universo entrevistado, 7 pessoas têm formação no ensino superior, e os demais, ensino médio e técnico. Verificou-se que 6 entrevistados atuam no setor administrativo, e os demais, nas áreas operacionais. A média do tempo trabalhado na última empresa é de 26 anos, o que evidencia que são pessoas com longo tempo dedicado às organizações industriais do setor privado.

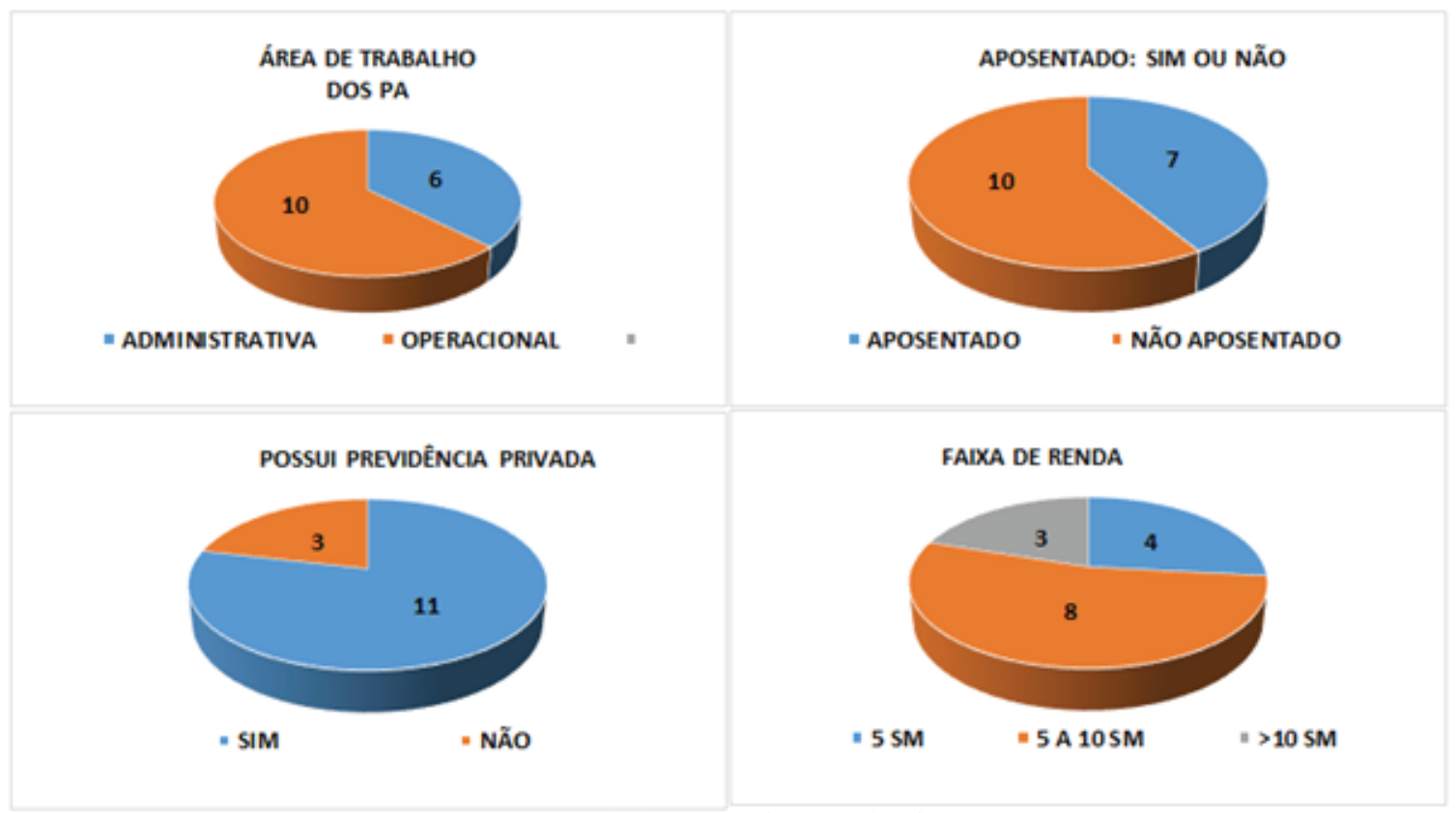

Figura 3 - Características profissionais dos participantes

Fonte: Elaborada pela autora a partir de dados coletados (2019).

Já aposentados são 7 trabalhadores, e 10 estão no período de até 5 anos para obtenção do direito ao benefício previdenciário. Três participantes têm o tempo de contribuição necessário para a aposentadoria, dois deles faltam 2 anos e os sete restantes estarão sujeitos às novas regras de transição para aposentadoria e terão que trabalhar mais tempo do que haviam previsto.

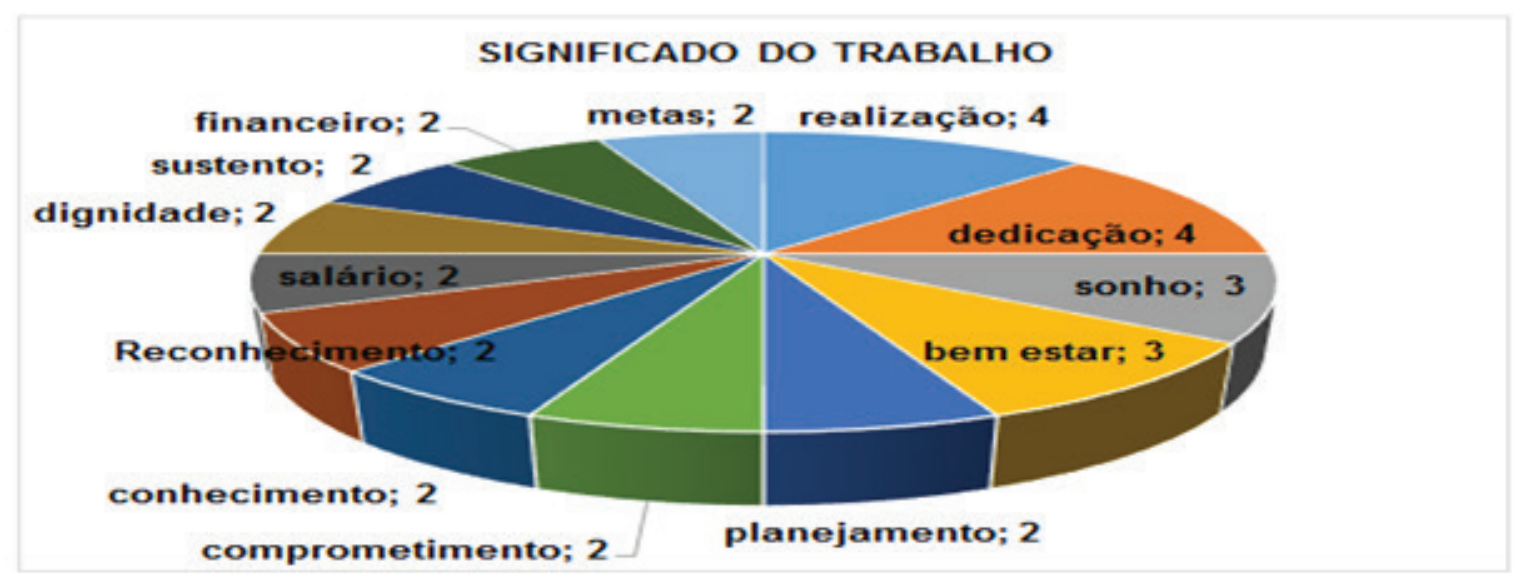

Figura 4 - Palavras descritivas do significado do trabalho

Fonte: Elaborada pela autora a partir dos dados coletados (2019). 
Todos os entrevistados exercem atividades profissionais, e apenas 2 não atuam na mesma empresa, em atividades diferentes das que exerciam antes da aposentadoria.

As principais palavras mencionadas pelos participantes, quando questionados a respeito do trabalho, foram: realização, dedicação, sonho, bem estar, planejamento, comprometimento, conbecimento, reconbecimento, salário, dignidade, sustento, financeiro e metas. As palavras mencionadas em relação à aposentadoria foram: benefício, ciclo vencedor, conquista, conquista pessoal, continuar trabalhando, descanso, dever cumprido, experiência, missão cumprida, mudança de fase, novo ciclo, recompensa e vitória.

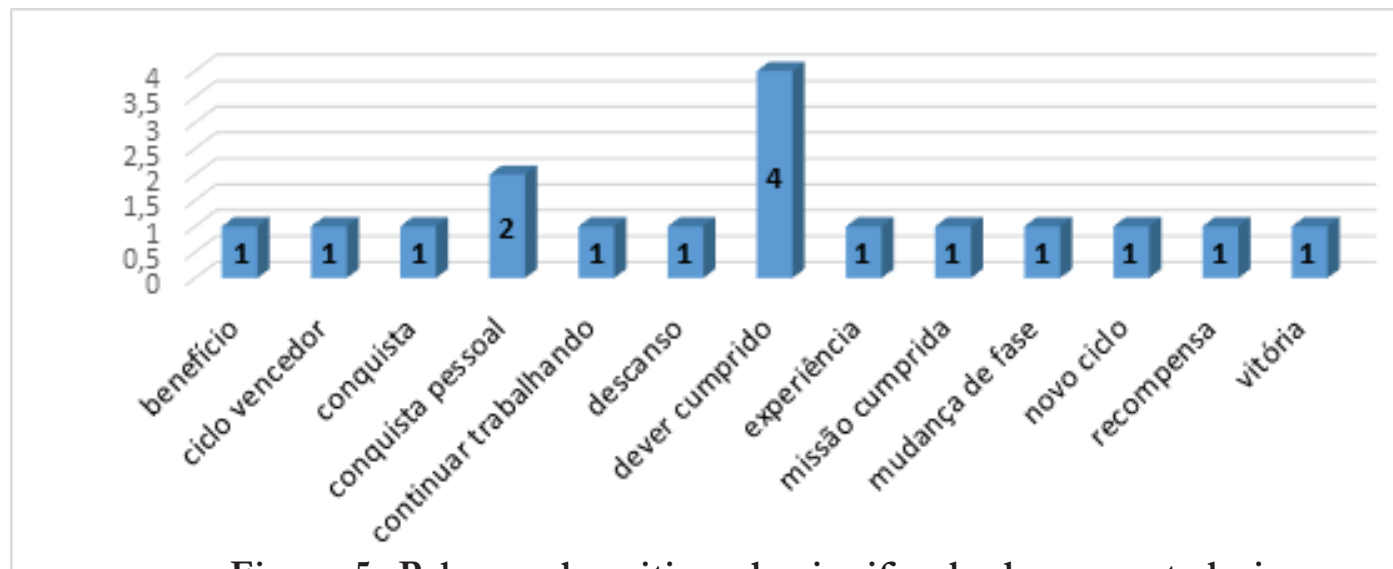

Figura 5- Palavras descritivas do significado da aposentadoria

Fonte: Elaborada pela autora a partir dos dados coletados (2019)

As palavras mencionadas pelos participantes, quando questionados sobre a expectativa da aposentadoria foram: descanso, saúde, lazer e dever cumprido.

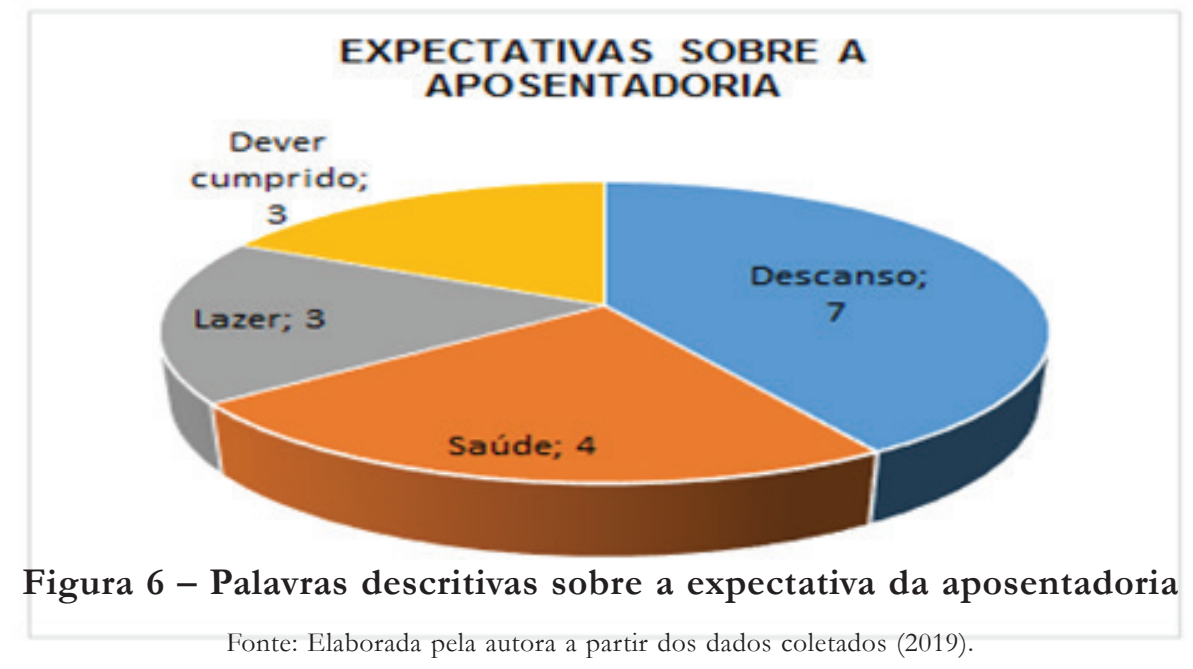

Os participantes informaram as palavras financeiro e plano de saúde para representar o aspecto de maior preocupação em relação à aposentadoria, e os profissionais de RH mencionaram as palavras financeiro e ocupação do tempo.

PARTICIPANTES A PARTIR DE 45 ANOS

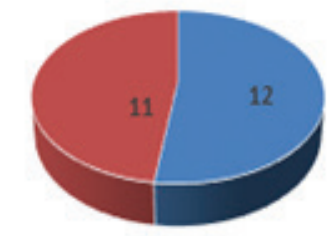

- financeiro - plano de saúde

\section{PROFISSIONAIS DE RH}

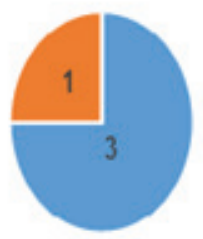

- Financeiro "Ocupação do tempo

Figura 7 - Palavras que correspondem a preocupação quanto à aposentadoria Fonte: Elaborada pela autora a partir dos dados coletados (2019). 
Em relação aos PPA a visão da maior parte dos trabalhadores com idade a partir de 45 anos e dos profissionais de RH envolvidos em PPA são semelhantes, quanto à relevância da orientação e do planejamento para a fase de aposentadoria e ruptura definitiva com o mercado de trabalho.

O fato de todos os participantes estarem atuantes no mercado de trabalho, maioria deles na mesma organização, trouxe pequena ênfase quanto à participação em PPA.

\section{Discussão}

A análise e interpretação de dados qualitativos é um processo sistemático, e a organização em categorias permite e facilita a atribuição de significados para a compreensão da realidade pesquisada (Oliveira, 2007). Nesse intuito, as categorias exploradas foram gestão, aposentadoria e preparação para aposentadoria, divididas nas subcategorias expectativa de carreira, significado do trabalho, significado da aposentadoria, expectativas sobre a aposentadoria, ganhos e perdas da aposentadoria e percepção sobre a relevância de PPA.

A respeito da política previdenciária que traz a redução dos valores de benefícios previdenciários e o adiamento da idade para aposentadoria, Camarano (2001) pondera que ela pode impactar na participação do idoso no mercado de trabalho. A partir do cenário econômico atual e das políticas adotadas pelas empresas, os profissionais aposentados podem ser preteridos em relação aos profissionais mais jovens, apesar de sua vasta experiência profissional e de seu conhecimento adquirido ao longo da jornada de trabalho.

Todos os participantes da presente pesquisa exercem atividade remunerada e, de acordo com 2 entrevistados, a decisão de continuar trabalhando está apoiada na necessidade de complementar a renda. Entretanto, nem sempre a decisão de continuar trabalhando após a aposentadoria compete ao trabalhador. Cepellos e Tonelli (2017) afirmam que as demissões em função da idade e dos altos salários é uma realidade no mercado de trabalho. Guides (2016) ressalta que o ageísmo, que está evidenciado na sociedade brasileira, demonstra o preconceito que oportuniza a desigualdade.

Dos 12 participantes que expressaram desejo de continuar trabalhando, 7 têm plano de Previdência Privada. A renda em salários-mínimos destes aposentados foram: 3 têm ou já tiveram renda superior a 10 salários-mínimos, 6 estão na faixa de 5 a 10, 2 têm renda de até 5 e 1 não respondeu à questão.
A maior parte dos participantes que pretendem continuar no mercado de trabalho planejou o complemento de renda para a aposentadoria por meio da Previdência Privada. Assim, têm um rendimento superior ao teto do benefício previdenciário pago atualmente na forma de aposentadoria por tempo de contribuição ou idade. A predominância do arranjo familiar entre os que consideram continuar trabalhando após a aposentadoria é aquele formado pelo casal e dois filhos.

O fato de os participantes optarem por deixar definitivamente o mercado de trabalho, após aquisição do benefício previdenciário, vai ao encontro da pesquisa de França, Menezes, Bendassolli e Macedo (2013) sobre os preditores da decisão em aposentar-se. $\mathrm{O}$ fato de estar cansado de trabalhar, o pensamento de dever cumprido e a oportunidade de priorizar o tempo com a família e cuidados com a saúde contribuem para o indivíduo decidir por romper com as atividades laborais.

Conforme pesquisa de Dutra, Costa e Sampaio (2016), sobre a percepção de saúde e qualidade de vida entre trabalhadores ativos e afastados do trabalho atendidos nas Unidades Básicas de Saúde (UBS) de Uberaba (MG), onde foram estudados 111 trabalhadores, estar fora do mercado de trabalho pode estar associado a uma pior percepção de saúde e qualidade de vida. Tal fato demonstra a necessidade de se promover plena inserção do adulto em atividades laborais, uma vez que pior percepção de saúde e qualidade de vida são fortes preditores de morbimortalidade.

Em relação ao significado do trabalho, as palavras recorrentes nas falas dos participantes são dedicação e realização, por ordem de recorrência, entretanto foram mencionadas 59 palavras diferentes.

A palavra financeiro, que aparece em terceiro lugar, por ordem de repetição, e as palavras salário, sustento, estabilidade econômica e remuneração passam a compor a maioria do significado do trabalho para os participantes da pesquisa. A diversidade de palavras encontradas pode demonstrar o sentido para cada indivíduo, conforme seu histórico de vida e trajetória profissional (Sá \& Lemos, 2017). Na questão direta sobre o significado do trabalho, verifica-se predominância da palavra financeiro, seguida da palavra sonhos.

É válido ressaltar que $88 \%$ das pessoas entrevistadas fazem parte de uma população assalariada. Vivem de sua força de trabalho como mercadoria, em troca de salário, participando diretamente da criação de valor agregado (Morin, Tonelli \& Vieira Pliopas, 2007).

Destaca-se o sentido do trabalho como uma questão que influencia na escolha feita pelo trabalhador maduro, 
que pode ser motivada por busca de propósito, desejo de flexibilidade, maior equilíbrio entre a vida pessoal e vida profissional e resgate de sonhos. Entretanto, todos os caminhos percorridos levam a remunerações menores do que aquelas que tinham antes da aposentadoria (Cepellos \& Tonelli, 2017).

A participação do idoso brasileiro no mercado de trabalho é alta, em relação aos padrões internacionais. Isso está relacionado a uma particularidade muito específica do mercado de trabalho brasileiro: a volta do aposentado ou a sua não saída do mercado de trabalho (Camarano, 2001).

É importante notar que a prática das aposentadorias incentivadas (França \& Soares, 2009) dispensa trabalhadores que adquiriram o direito ao benefício da Previdência Social referente à aposentadoria por tempo de serviço. $\mathrm{Na}$ maioria das vezes sem a preparação para uma nova fase da vida.

Essa incipiência em relação à orientação e ao planejamento para a ruptura com o mercado formal de trabalho também pode influenciar a organização da carreira profissional e a continuidade dos projetos nas organizações, bem como o tema aposentadoria poderá ser percebido como um tabu entre a empresa e o trabalhador.

A falta de um processo estruturado e difundido como política de Recursos Humanos nas organizações pode desencadear encurtamento de carreira e demissão. Fato que ocorre, na iniciativa privada, com os profissionais próximos aos cinquenta anos de idade (Seidl \& Conceição, 2014).

Em relação à transferência de conhecimento e preparação de sucessores, o fato de a maioria dos participantes continuar no mercado de trabalho, e em grande parte na mesma empresa, pode acarretar certa apreensão aos que estão prestes a se aposentar ou que já estão aposentados. Apesar de a maioria dos participantes afirmar que prepara pessoas para a substituição, nenhum deles apresentou um planejamento concreto para a transferência do conhecimento adquirido ao longo dos anos, e alguns deles afirmam ser este um papel da empresa.

O bridge employment poderia ser uma alternativa na fase de transição do trabalho para a aposentadoria definitiva, por proporcionar maior autonomia e permitir aos trabalhadores e às organizações um formato flexível para garantir a transferência de conhecimento adquirido ao longo da permanência na empresa (Kim \& Feldman, 2000).

A peculiaridade do processo de aposentadoria tem início a partir da pré-aposentadoria e se estende até o fim da vida do indivíduo (Bitencourt, Gallon, Batista \& Piccinini, 2011). Para a maioria dos participantes da pesquisa, a aposentadoria representa dever cumprido.

Considerando as novas regras da Previdência Social para a aposentadoria, como o aumento da idade, os participantes passaram a entendê-la como conquista, possivelmente pelo fato de que ela está agora alguns anos mais distantes para os que terão que cumprir os novos critérios de idade.

Verifica-se que os vários significados para aposentadoria apontados pelos participantes vão ao encontro das observações de Leandro-França (2014): a percepção e vivência da aposentadoria são influenciadas por aspectos internos e externos que envolvem condições associadas às situações pessoais, psicossociais e organizacionais. Há, pois, necessidade de desenvolvimento de características que sejam fatores de proteção para a transição para aposentadoria, diminuindo assim as vulnerabilidades desse período.

Os termos mais utilizados pelos participantes, a respeito de sua expectativa sobre a aposentadoria, foram descanso, saúde, lazer e dever cumprido, por ordem de maior número de repetições.

O paradoxo presente na fala dos participantes, no que diz respeito ao descanso, e quanto às questões anteriores sobre a intenção de continuar trabalhando, denota que pode haver ausência de reflexão e de planejamento para conquistar o almejado descanso na aposentadoria. Seidl e Conceição (2014) afirmam que, para as pessoas estarem em sintonia com seus valores, devem refletir se querem e como querem traçar novas perspectivas para o período pós-aposentadoria.

Existem diversas formas de se perceber a aposentadoria que podem representar um novo começo, mais tempo para relacionamentos familiares e sociais, atividades de cultura e lazer, com possibilidades de mudança de estilo de vida, inclusive com a opção de continuar trabalhando (França \& Amorim \& Souza \& Schuabb, 2017). Entretanto, Cepellos (2013) evidenciou, em sua pesquisa junto a gestores de Recursos Humanos, que as empresas não estão preparadas para o envelhecimento da força produtiva.

$\mathrm{Na}$ fala dos participantes nota-se que as expressões qualidade de vida, tempo para a família e saúde aparecem em maior número de vezes, quando se referem aos ganhos com o processo de aposentadoria. Os participantes que responderam dessa forma pertencem majoritariamente ao grupo dos que têm formação de nível superior e que já estão aposentados, ou seja, recebem benefícios da Previdência Social. 
Pesquisa realizada na Universidade da Califórnia evidenciou que idade, sexo, condição de saúde, condição socioeconômica, condição geral do parceiro e características do emprego são preditores que podem reter os trabalhadores maduros por mais tempo no mercado de trabalho. O baixo salário e a idade avançada estão inversamente relacionados com a permanência no trabalho (França, Menezes, Bendassolli \& Macedo, 2013). É interessante notar que os participantes da pesquisa aqui relatada continuam com suas atividades laborais, seja em organizações privadas, seja no empreendedorismo.

Em relação às perdas no processo de saída definitiva do mercado de trabalho, percebe-se apreensão quanto a convênio médico, convivência com os colegas e aspecto financeiro, por parte da maioria dos respondentes que pertencem ao grupo com formação de ensino médio e técnico e que já recebe benefício previdenciário.

Os trabalhadores que decidirem continuar no mercado de trabalho após a aposentadoria poderão continuar motivados, no entanto alguns desejam ou necessitam se aposentar para aproveitar o tempo para lazer, cuidar da saúde, dos relacionamentos sociais e familiares, ou para realizar outra atividade profissional que lhes traga maior satisfação (França \& Soares, 2009).

Vale salientar que, segundo pesquisas realizadas com trabalhadores de Uberaba (MG), ativos e afastados, o afastamento do mercado de trabalho está associado a uma pior percepção de saúde e qualidade de vida para os trabalhadores inativos (Dutra, Costa \& Sampaio, 2016). Tal fato se torna relevante no planejamento para ocupação do tempo disponível após a saída do mercado de trabalho.

Os resultados da pesquisa realizada com trabalhadores de uma instituição governamental e seus cônjuges demonstraram que aspectos como cuidar de outra pessoa, idade limite para aposentadoria, trabalho voluntário e religião foram considerados preditores para a decisão de aposentar-se, além do aspecto financeiro (Beehr, Glazer, Nielson \& Farmer, 2000).

É importante notar que há um contraponto a respeito da percepção sobre a aposentadoria, pois, embora haja a expectativa de buscar a qualidade de vida e dispor de mais tempo para a família e até mesmo para os amigos, existe preocupação quanto a diminuição da renda e manutenção do convênio médico, que hoje, para os participantes que estão atuantes no mercado de trabalho, é subsidiado pela empresa em grande parte de seu valor. Hoje existem mais pessoas aposentadas do que as de duas gerações anteriores. Entretanto os custos com a saúde estão avançando além da taxa de inflação.
Por esse motivo, o planejamento para a aposentadoria torna-se muito mais desafiador (Feldman \& Beehr, 2011).

Os vários espaços sociais demonstram interesses nas questões relacionadas à fase tardia da vida, mas a aposentadoria continua sendo um evento estressante, pois gera alterações nos diversos domínios de vida das pessoas (Antunes, Moré \& Schneider, 2016). Por isso, os profissionais de Recursos Humanos devem trabalhar em conjunto com a comunidade acadêmica, para encontrar formas de estimular a diversidade na organização. França (2008) pondera que o mercado ainda apresenta preconceitos que precisam ser discutidos com trabalhadores, empresários, trazendo o Profissional de Recursos Humanos como facilitador dessa discussão (Brito, França \& Valentini, 2016).

As respostas dos Profissionais de RH vão ao encontro das respostas dos demais participantes, quando questionados a respeito do aspecto que lhes traz maior preocupação, em relação ao advento da aposentadoria. Nas falas dos participantes aparecem as palavras financeiro e convênio médico, e na fala dos Profissionais de $\mathrm{RH}$ predomina a palavra financeiro.

O trabalhador que elabora um projeto de vida para aposentadoria poderá dispor de mais condições para adaptação do que aquele que sabe o que irá fazer quando se aposentar (França, Barbosa \& Murta, 2014). Para entender a compreensão dos participantes e dos profissionais de RH envolvidos em PPA, perguntou-se a eles sobre sua participação ou desejo de participar, assim como sobre a contribuição dos PPA para o planejamento da aposentadoria.

As respostas dos participantes a respeito de já terem participado ou de seu interesse em participar de PPA foi igualmente distribuída. Os que não participaram dos PPA não conseguem apresentar opinião a respeito, mas consideram-nos relevantes para o processo de aposentadoria.

De fato, no início os PPA não apresentavam um conteúdo que apoiasse a decisão de aposentar-se, nem o acompanhamento necessário nesse período (Zanelli, Silva \& Soares, 2009). As ações nesse sentido ampliaram-se a partir de 2009, com o Estatuto do Idoso. Os PPA podem ser uma chance para que os trabalhadores que desejam se aposentar planejem sua decisão e façam o processo de transição.

Para a organização, pode significar um novo aprendizado e oportunidade de estreitar o relacionamento com os profissionais. Para os profissionais, oportuniza reconhecimento e alerta para problemas que a lógica do sistema produtivo pode ocultar (Zanelli, Silva \& Soares, 2009). 
Para entender a percepção dos profissionais de RH envolvidos em PPA, perguntou-se a eles a respeito da contribuição desses programas para os profissionais que estão próximos da fase de aposentadoria.

Os profissionais de Recursos Humanos entendem que a aposentadoria ainda é um tema delicado e difícil de ser abordado entre a liderança e os trabalhadores, nas organizações, e isso pode gerar resistência na implantação de PPA. Entretanto, reconhecem a relevância da educação para aposentadoria e pontuam que, se for bem estruturada e conduzida, pode contribuir para a transição de carreira dos trabalhadores e favorecer a empresa no cumprimento de seu papel social.

Foi unânime o entendimento dos profissionais de RH a respeito do fato de que os Programas de PPA podem servir como apoio às empresas, no que se refere à preparação de seus profissionais, desde o início até o final de suas carreiras. É interessante ressaltar que essa iniciativa pode figurar, inclusive, como responsabilidade social da empresa.

Em relação aos aspectos dificultadores envolvidos nos PPA foi considerado o fato de que pode ser oferecido um programa já pronto, sem considerar as especificidades e necessidades do trabalhador. Tal fato pode ocasionar o não atingimento dos objetivos da educação para aposentadoria. Isso porque, para compreensão do processo da aposentadoria nos diferentes grupos sociais, é preciso analisar o tipo e a natureza do trabalho realizado, assim como as diversas expectativas de vida existentes no país, que são consequências da desigualdade social (França, Nalin, Siqueira-Brito, Amorim, Rangel \& Ekman, 2014).

Outro aspecto dificultador apontado foi o tempo necessário para que se possa aplicar o PPA. Normalmente a estrutura do programa se estende por alguns meses, sendo necessário investimento em médio prazo, por parte das empresas.

Ainda como aspecto dificultador foi apresentado o fato de que o assunto ainda é um tabu nas organizações que não incorporaram o tema como um projeto para cuidar dos profissionais, desde o início de suas carreiras até o seu ciclo final, o que gera desconforto para a liderança e para os trabalhadores.

A pesquisa de Cepellos e Pereira Filho (2018), realizada em 2013, com mais de cem empresas, verificou que as práticas que contribuem para a melhor gestão do profissional maduro eram pouco adotadas no âmbito organizacional. Essa situação ocorre por conta do preconceito em relação à idade, que tem sido denominado globalmente de ageism.
A visão da maioria dos trabalhadores com idade a partir de 45 anos participantes da pesquisa e dos profissionais de Recursos Humanos envolvidos em PPA são convergentes, quanto à relevância da orientação e do planejamento para a fase de aposentadoria e ruptura definitiva com o mercado de trabalho.

O fato de todos os participantes estarem atuantes no mercado de trabalho e, em sua maioria, na mesma organização, trouxe pequena ênfase quanto à participação em PPA. Nesse sentido, a mudança nas atividades e na rotina ainda é uma situação desconhecida para os participantes que ainda não vivenciaram a possível perda de poder, prestígio, autoestima e relacionamentos sociais. Não vivenciaram também o desconforto em suas próprias casas e na relação com seus parceiros no dia a dia (França, 2008).

Os participantes que atuam em atividades diferentes após a saída da organização e aposentadoria não tiveram a oportunidade de participar de PPA. Assim, perceberam a ausência de orientações no desligamento contratual e o fato de não se sentirem reconhecidos profissionalmente.

Apesar de considerados como práticas relevantes, pelos gestores, e de estarem respaldados em leis, os PPA ainda não são amplamente realizados nas organizações brasileiras (Leandro-França, 2016).

A pré-aposentadoria é passível de constituir fator de integração entre as pessoas, se for conduzida na forma de grupos e com estratégia de compartilhamento. Desse modo, o programa seria parte de um processo direcionado à reintegração do indivíduo ao meio social, com base no respeito ao ser humano e na consciência dos prejuízos que podem ser ocasionados pelo rompimento brusco das rotinas de trabalho (Zanelli, Silva \& Soares, 2009).

Cabe salientar que a ampliação dos PPA pode contribuir para à preparação dos trabalhadores em relação às suas ansiedades e temores e quanto à carreira e ao futuro, especialmente quanto ao aspecto financeiro. Pode propiciar também a oportunidade de a organização, por meio dos seus gestores, demonstrar o reconhecimento e o cuidado com os trabalhadores que dedicaram sua juventude e sua força de trabalho, com comprometimento, para o sucesso da empresa.

\section{Considerações finais}

A aproximação do direito ao benefício previdenciário pode trazer anseios e receios ao indivíduo, no momento de tomar a decisão de aposentar-se em definitivo, de permanecer no mesmo trabalho ou de adotar o bridge employment - trabalho de ponte. 
Os trabalhadores demonstraram o significado do trabalho e sua importância por meio das palavras dedicação e realização. Quando questionados sobre as 5 primeiras palavras que pensam em relação ao trabalho, as respostas relacionaram-se ao aspecto financeiro: salário, sustento, estabilidade econômica e remuneração. Percebe-se, portanto, que o significado do trabalho pode se apresentar de diferentes maneiras, dependendo da trajetória de carreira e do histórico de vida de cada um, e que o aspecto financeiro se sobressai aos demais.

Em relação às expectativas de carreira e aposentadoria, verificou-se que apenas 5 participantes pretendem sair definitivamente do mercado de trabalho e 12 desejam continuar exercendo atividades, dentre os quais alguns mencionam que pretendem praticar atividades diferentes das que realizam hoje.

A decisão pela ruptura das atividades laborais está apoiada no desejo de ter maior tempo disponível para a família, melhor qualidade de vida e manutenção da saúde. Os que pretendem continuar trabalhando, em sua maioria, afirmam a necessidade de complementar a renda do benefício previdenciário.

Quanto à continuidade dos projetos que estão em andamento e à preparação de substitutos para as atividades que realizam, $85 \%$ dos participantes afirmam que há uma preparação, entretanto não informaram ter um processo estruturado e planejado para suportar a sucessão. Entendem que se trata de uma responsabilidade da empresa e dos gestores. Esse fato pode denotar uma postura defensiva e o receio de que a empresa possa realizar a aposentadoria compulsória.

Os resultados obtidos sugerem novas pesquisas, que podem ser conduzidas com profissionais que participaram de PPA, assim como por profissionais que romperam definitivamente com as atividades laborais, a fim de analisar as percepções posteriores às orientações e ao planejamento para a aposentadoria.

\section{Referências}

Albuquerque, E. M. (2009) Repositório Institucional da Fiocruz. Avaliação da técnica de amostragem respondent-driven sampling na estimação de prevalências de doenças transmissiveis em populações organiz̧adas em redes complexas. Disponivel em: <https://www.arca.fiocruz.br/handle/icict/2411>. Acesso em: 12 jul. 2019.

Antunes, M. H., More, C. L. O. O. \& Schneider, D. R. (2016).Compreendendo o fenômeno da aposentadoria em uma perspectiva relacional: contribuições do pensamento sistêmico. Pensando familias, v. 20, pp. 70-84.

Bardin, L. (1977) Análise de conteúdo. Lisboa: Edições 70.

Beehr, T. A.; Glazer, S.; Nielson, N. L.; Farmer, S. J. (2000).Work and nonwork predictors of employees retirement ages. Journal of Vocational Behavior, Calgary, n. 57, p. 206-225.

Bitencourt, B. M.; Gallon, S.; Batista, M. K.; Piccinini, V. C.(2011). Para além do tempo de emprego: o sentido do trabalho no processo de aposentadoria. Ciências da Administração, p. 30-57.
Bressan, M. A. L. C.; Mafra, S. C. T.; França, L. H. de F. P.; Melo, M. S. de S.; Loreto, M. das D. S. de (2012). Trabalho versus aposentadoria: desvendando sentidos e significados. Família e Sociedade em Debate, v. 23, n. 1, p. 226-250.

Brito, A. D. R. S.; França, L. H. D. F. P.; Valentini, F. (2016). Análise fatorial confirmatória da Escala de Ageismo no Contexto Organizacional. Avaliaçao Psicologica: Interamerican Journal of Psychological Assessment, v. 15, n. 3, p. 337-345.

Camarano, A. A. (2001). O idoso brasileiro no mercado de trabalho. Disponivel em: <http://repositorio.ipea.gov.br/handle/11058/2068>. Acesso em: 10 jul. 2019.

Cepellos, V. M. (2013). O envelhecimento nas organizaç̧ões: das percepções de gestores de recursos humanos às práticas de gestão da idade. Disponivel em: <https://bibliotecadigital.fgv.br/dspace/handle/10438/10588>. Acesso em: 25 maio 2019.

Cepellos, V. M.; Tonelli, M. J. (2017). Envelhecimento profissional: percepções e práticas de gestão da idade. Revista Alcance, v. 24, n. 1, p. 4-21.

Cepellos, V.; Pereira Filho, J. L. (2018). Envelhecimento nas empresas. GV-executivo, v. 17, n. 2, p. 50. Disponivel em: <http://bibliotecadigital.fgv.br/ ojs/index.php/gvexecutivo/article/viewFile/74751/71558>.

Dantas, P. M. D. A. B.; De Oliveira, C. M. (2014). Programas de preparação para aposentadoria: desafio atual para a gestão de pessoas. Argumentum, v. 6, p. 116-132.

De Oliveira Borges, L.; Tamayo, Á. (2001). A estrutura cognitiva do significado do trabalho. Psicologia: organizaçoes e trabalho, v. 1, n. 2, p. 11-44.

Dutra, F. C. M. S.; Costa, L. C.; Sampaio, R. F. (2016). A influência do afastamento do trabalho na percepção de saúde e qualidade de vida de indivíduos adultos. Fisioterapia e Pesquisa, 23, n. 1, 98-104.

Feldman, D. C.; Beehr, T. A. (2011). A Three-Phase Model of Retirement Decision Making. American Psychologist, v. 66, n. 3, p. 193-203.

França, L. (2008). O desafio da aposentadoria: o exemplo dos executivos do Brasil e da Nova Zelândia. Rio de Janeiro: Rocco.

França, L. H. D. F. P.; Menezes, G. S.; Bendassolli, P. F.; Macedo, L. S. S. (2013). Aposentar-se ou continuar trabalhando?: o que influencia essa decisão. Psicologia: ciência e profissão, v. 33, n. 3, p. 548-563.

França, L. H. D. F. P.; Nalin, C. P.; Siqueira-Brito, A. R.; Amorim, S. M. (2014). A percepção dos gestores brasileiros sobre os programas de preparação para a aposentadoria. Estudos Interdisciplinares sobre o Envelhecimento, p. 1-20.

França, L. H. D. F. P.; Amorim, S. M.; Souza, A. P.; Schuabb, T. C. (2018). Autobiografia orientada para avaliar vida, carreira e planejar para a aposentadoria. Rev. bras. orientac. prof, p. 249-258, 2017. Disponivel em: <http://pepsic. bvsalud.org/scielo.php?script=sci_arttext\&pid=S1679-33902017000200011>. Acesso em: 24 jul. 2018.

França, L. H. D. F. P.; Barbosa, L. M.; Murta, S. G. (2014). Projetos de vida, valores e ação comprometida na aposentadoria. In: MURTA, S. G.; LEANDRO-FRANÇA, C.; SEIDL, J. Programas de educação para aposentadoria. Novo Hamburgo: Sinopsys, p. 320.

França, L. H. D. F. P.; Soares, D. H. P. (2009). Preparação para a aposentadoria como parte da educação ao longo da vida. Psicologia: ciência e profissão, v. 29, n. 4, p. 738-751.

Guides, A. C. D. S. (2016). O idadismo sob a escuta dos idosos: efeitos de sentido e a utopia de um novo envelhecer. Pontifícia Universidade Católica de São Paulo. São Paulo, p. 101.

Kim, S.; Feldman, D. C. (2000). Working in retirement: the antecedents of bridge employment and its consequences for quality of life in retirement. Disponivel em: https://www.jstor.org/stable/1556345? seq=1. Acesso em: 10 jul. 2019.

Leandro-França, C. (2014). Aposentadoria: crise ou liberdade? In: MURTA, S. G.; Programas de educação para aposentadoria. Novo Hamburgo: Sinopsys, p. $54-65$.

Leandro-França, C. (2016). Efeito de programas de preparação para aposentadoria: um estudo experimental. 291f. Tese de Doutorado (Programa de Pós-Graduação em Psicologia Clínica e Cultura) Universidade de Brasília, Brasília, DF.

Morin, E.; Tonelli, M. J.; Vieira Pliopas, A. L. (2007). O trabalho e seus sentidos., v. 19, n. 1, 2007. Psicologia \&o sociedade, p. 1-11.

Oliveira, A. L. D. (2007). Comportamento organizacional e pesquisa qualitativa: algumas reflexões metodológicas. In: CHAMON, E. M. Q. D. O. Gestão e comportamento bumano nas organizações. Rio de Janeiro: Brasport. Cap. 7, p. 205. 
Sá, J. G. S. D.; Lemos, A. H. D. C. (2017). Sentido do Trabalho: Análise da Produção Científica Brasileira. Revista ADM.MADE, p. 21-39.

Seidl, J.; Conseição, M. I. G. (2014). Identidade, valores e novas perspectivas profissionais. In: MURTA, S. G.; LEANDRO-FRANCA, C.; SEIDL, J. Programas de educação para aposentadoria. Novo Hamburgo: Sinopsys, p. 320.

Varela, M. D. G. D. A. (2013). Significado do trabalho e aposentadoria: em estudo entre os docentes de uma Instituição Federal de Ensino. Dissertaçao (Mestrado Profissional em Administração) - Universidade Potiguar. Natal, p. 151
Zanelli, J. C.; Silva, N.; Soares, D. H. P. (2009). Orientação para aposentadoria nas organizações de trabalho: construção de projetos para o pós-carreira. Porto Alegre: Artmed, 2009

Submetido em: 2-8-2020

Aceito em: 27-2-2021 